Recepción: 20 / 04 / 2017

Aceptación: 20 / 05 / 2017

Publicación: 15 / 06 / 2017
Ciencias de la Salud

Artículo de Investigación

\title{
Tipos de superficie en los implantes dentales
}

\author{
Types of surface in dental implants
}

Tipos de superfície nos implantes dentales

\author{
Víctor H. Silva-Miranda ${ }^{\mathrm{I}}$ \\ contacto@odontosolution.com \\ Patricia del Pilar Astudillo-Campos II \\ _patricia.astudilloc@ug.edu.ec \\ María V. Vélez-Sánchez III \\ maria.velezs@ug.edu.ec \\ Martha N. Sánchez-Valdiviezo IV \\ martha.sanchezv@ug.edu.ec
}

Correspondencia: contacto@odontosolution.com

I. Doctor en Odontología, Especialista en Implantología, Diploma Superior en Implantologia, Universidad de Guayaquil, Guayaquil, Ecuador.

II. Diploma Superior en Diseño Curricular por Competencias, Especialista en Endodoncia, Diplomado en Docencia Superior, Docente Universidad de Guayaquil, Guayaquil, Ecuador.

III. Doctora en Odontología, Diplomado en Docencia Superior, Magister en Docencia y Gerencia en Educación Superior, Docente Universidad de Guayaquil, Guayaquil, Ecuador.

IV. Magister en Docencia y Gerencia en Educación Superior; Diplomado en Docencia Superior; Diplomado en Docencia Superior; Doctora en Odontología; Universidad de Guayaquil, Guayaquil, Ecuador. 


\title{
Resumen
}

La terapia con implantes dentales es hoy en día una excelente alternativa de tratamiento para remplazar los dientes perdidos, propuesta cada vez más aceptada por los pacientes y los profesionales de la odontología. Las investigaciones se concentran en conseguir resultados más predecibles y sostenibles a lo largo del tiempo. Los implantes dentales desde sus inicios han evolucionado en el diseño tanto de su macro y micro topografía con la finalidad de tener una mejor oseointegración. En este trabajo de revisión, presentamos los diferentes aspectos de la respuesta biológica de los implantes dentales, destacar las propiedades del titanio comercialmente puro y exponer los diferentes métodos de tratamiento de superficie. Se han publicado en la literatura diversos trabajos de investigación relacionados en conseguir superficies cada vez más bioactivas, dando al implante propiedades osteoconductoras reduciendo los tiempos de cicatrización, y así obtener una oseointegración más rápida y sostenible.

Palabras clave: Implantes dentales; dientes perdidos; oseointegración; osteoconductoras.

\begin{abstract}
Dental implant therapy is nowadays an excellent treatment alternative to replace lost teeth, a proposal increasingly accepted by patients and dentists. Research is focused on achieving more predictable and sustainable results over time. Dental implants since its inception have evolved in the design of both its macro and micro topography in order to have a better osseointegration. In this review, we present the different aspects of the biological response of dental implants, highlight the properties of commercially pure titanium and expose the different surface treatment processes. A number of research papers have been published in the literature related to achieving increasingly bioactive surfaces, giving the implant osteoconductive properties, reducing healing times, thus achieving a more rapid and sustainable osseointegration.implante redução dos tempos de cura, e obter uma osseointegração mais rápida e sustentável.
\end{abstract}

Key words: Dental implants; teeth lost; osseointegration; osteoconductors.

\section{Resumo.}

A terapia de implantes dentários é hoje uma excelente alternativa de tratamento para substituir os dentes perdidos, uma proposta cada vez mais aceita por pacientes e dentistas. A pesquisa está focada em alcançar resultados mais previsíveis e sustentáveis ao longo do tempo. Os implantes dentários desde a sua criação evoluíram no desenho de sua topografia macro e micro, a fim de ter uma melhor ressecção osseointegrada. Nesta revisão, apresentamos os diferentes aspectos da resposta biológica dos implantes dentários, destacamos as propriedades do titânio comercialmente puro e expõe os diferentes processos de tratamento de superfície. Uma série de trabalhos de pesquisa foram publicados na literatura relacionados à obtenção de superfícies cada vez mais bioativas, proporcionando propriedades osteocondutoras do implante, reduzindo os tempos de cicatrização, conseguindo assim uma osseointegração mais rápida e sustentável.implante redução dos tempos de cura e obtenha uma osseointegração mais rápida E sustentável.

Palavras-chave: Implantes dentários; dentes perdidos; osseointegração; osteoconducção. 


\section{Introducción.}

La tecnología que se aplica a los implantes dentales se encuentra en continuo avance para conseguir una mejor interacción entre el hueso y la superficie del implante. Entre los materiales empleados para la fabricación de implantes dentales, el más usado es el titanio puro o las aleaciones de titanio, a causa de su probada biocompatibilidad y a toxicidad. Nunca se han señalado reacciones de tipo alérgico y/o inmunológicas causadas por la presencia de este metal.

Una de las propiedades que presenta el titanio es la posibilidad de formar una capa de óxido de titanio estable cuando se expone al aire, lo cual le da mayor resistencia a la corrosión. La capa de óxido se compone químicamente de distintos óxidos ( $\mathrm{TiO} 2, \mathrm{TiO}, \mathrm{Ti2} 23)$, aunque el más predominante y estable es el dióxido de titanio ( $\mathrm{TiO} 2)$. Al implante dental es sometido a un proceso conocido con el nombre de pasivación, esto otorga una elevada protección a las capas metálicas que están debajo, al no difundir iones en el ambiente por la elevada constante dieléctrica de la capa de óxidos, y en consecuencia proporciona una alta resistencia contra los agentes corrosivos. (1) (10)

Existen varios tipos de superficies en los implantes dentales, todos ellos buscando obtener una mejor osteointegración en el lecho quirúrgico. El biomaterial ideal que conformaría la superficie del implante debería ser aquel que además de biocompatible, y promueve la curación ósea.

Existen varias morfologías de la superficie de los implantes dentales, como son las lisas, las rugosas y las porosas. La superficie lisa vista bajo el microscopio se aprecian unas discretas rugosidades creadas por la herramienta de corte en su fabricación, esta particularidad y gracias a las propiedades del titanio, los implantes de superficie lisa presentan en las primeras etapas de la oseointegración una distribución de los osteoblastos en sentido de las ralladuras creadas en su fabricación. (Foto 1) Dentro de las superficies lisas, se encuentran las de mínima rugosidad (0,5 a 
$1 \mu \mathrm{m})$, las de rugosidad intermedia (1 a $2 \mu \mathrm{m})$, y las rugosas (2 a $3 \mu \mathrm{m})$. Pero en términos generales, una superficie es lisa cuando su rugosidad $(\mathrm{Sa})$ es igual o menor a $1 \mu \mathrm{m}$, y las rugosas son las mayores de $1 \mu \mathrm{m}$. Los implantes mecanizados de titanio son de superficie lisa, con una rugosidad de 0,53 a $0.96 \mu \mathrm{m}$, dependiendo de los protocolos de fabricación, grado del material, forma y afilado de las herramientas de corte. (29)

La calidad de la superficie del implante dental es uno de los factores clave para lograr una buena estabilidad y curación en la zona perimplantaria. Debe existir una buena interacción entre el tejido óseo, la geometría del implante y la textura de su superficie. Así, para mejorar la osteointegración, se han realizado ciertas modificaciones a su superficie con métodos de adhesión y de sustracción, intentando incrementar el área y la rugosidad de las superficies de los implantes.

Desde mediados de los años 80 se han recomendado distintos implantes revestidos con hidroxiapatita para su utilización en clínica. Este tipo de revestimiento, a diferencia de los implantes de titanio puro, acelera la cicatrización ósea y el contacto con el hueso perimplantario. Se ha demostrado en diversos estudios clínicos que este revestimiento se asocia a buenos resultados durante periodos de aproximadamente 5 años, con una media de respuesta favorable del $95 \%$ en este periodo.

Sin embargo, últimamente se han descrito cada vez más fracasos de los implantes recubiertos de hidroxiapatita y se evita su utilización clínica. A pesar de que la hidroxiapatita acelera la cicatrización ósea, ésta tiene una repercusión negativa a medio o largo plazo sobre la inestabilidad. Se han descrito fracturas, pérdidas totales del revestimiento, y colonización por microorganismos en algunos implantes recubiertos con hidroxiapatita que han sido extraídos. Cuando la hidroxiapatita entra en contacto directo con el medio bucal tras la degradación del hueso perimplantario, se 
producen aparentemente fracturas muy rápidas del hueso que rodea el implante. Por eso, hay que esperar el desarrollo de nuevas tecnologías de revestimiento con hidroxiapatita. (1) (10)

Entre los métodos por sustracción para aumentar la rugosidad de los implantes dentales está el chorreado (arenado) o granallado, que consiste en el lanzamiento de partículas abrasivas de diferente tamaño sobre la superficie del implante, consiguiendo producir asperezas en la superficie para mejorar la aposición ósea. Se han utilizado partículas de óxido de aluminio, carburo de silicio, óxido de titanio, étc.

Es necesario emplear tratamientos para remover los residuos, obligando frecuentemente a utilizar sucesivos baños o enjuagues con varias sustancias que en teoría reducirán las asperezas, picos y valles creados por el arenado. Una posible solución a este problema podría ser el uso de sustancias biocompatibles, como el fosfato tricálcico o la hidroxiapatita, que demandarán tratamientos menos radicales tras el proceso del arenado.

Otro método de sustracción es el grabado ácido. Los implantes dentales son sumergidos en soluciones con distintos ácidos: ácido clorhídrico (HCl), sulfúrico (H2SO4), nítrico (HNO3), fluorhídrico $(\mathrm{HF})$, que erosionan su superficie creando hoyos de diferentes formas y dimensiones, en función de las concentraciones de las soluciones ácidas, del tiempo y la temperatura. Este tratamiento, tiende a aumentar la superficie de contacto entre el hueso y el implante reduciendo el tiempo de cicatrización ósea.

Otro tratamiento de superficie consiste en realizar primeramente un chorreado o granallado y a continuación un grabado ácido, lo cual proporciona a la superficie del implante una media de rugosidad de $2 \mu \mathrm{m}$, mientras que la rugosidad de los implantes tratados sólo con grabado ácido es de 1,3 $\mu \mathrm{m}$. Es el caso de la superficie SLA de Straumann, tratada con chorreado de arena y grabada con 
ácido sulfúrico-hidroclorhídrico, siendo el método más utilizado y estudiado en los últimos diez años.

Otros métodos empleados para mejorar la osteointegración de los implantes son los electroquímicos, que producen modificaciones en la superficie por el efecto de adhesión o deposición química como lo es la oxidación anódica, esto le proporciona un aumento en la capa de óxido del implante y cambios en su composición química, con la presencia de calcio, fosfatos y fluoruros. También se están aplicando colágeno, acetatos de vinilo-etileno o poliláctico-glicólico en la superficie del implante con el fin de conseguir una mejor respuesta celular en la interfase implante-hueso. (8)

El tipo de superficie y el grado óptimo de rugosidad no se han desarrollado definitivamente todavía. La investigación está en continua evolución en el campo de los biomateriales y en el estudio de superficies bioactivas con el intento de acelerar y mejorar los fenómenos de integración entre implantes y tejidos.

Hoy en día, la utilización de implantes de titanio comercialmente puro representa un estándar tradicional y un parámetro de referencia y comparación para la evaluación de otros materiales o tratamientos de superficie, dado que los estudios experimentales y clínicos que utilizan dichos métodos ostentan un seguimiento de más de 20 años. 


\section{Metodología}

\section{La oseointegración en la implantología}

\section{Oseointegración}

En 1965, el equipo del profesor Per-ingvar Brånemark llevó a cabo un trabajo en el que se pretendía investigar la anatomía y la fisiopatología correspondientes a lesiones del tejido óseo y su microcirculación en una serie de tibias de conejos. Con el objetivo de evaluar los cambios tisulares bajo condiciones experimentales controladas, concretamente a través de una microscopía de observación, se ubicaron dentro del hueso cámaras cuyas carcasas estaban fabricadas de titanio. El equipo sueco comprobó, que se podía conseguir una conexión firme entre el hueso y las carcasas de titanio, siempre y cuando el trauma ocasionado durante la cirugía fuese mínimo. De hecho, después de la cicatrización y la remodelación del tejido era imposible extraer las carcasas sin dañar al hueso circundante ya que la estructura del titanio se había incorporado completamente en el hueso, y el tejido óseo mineralizado era totalmente congruente con las irregularidades de la superficie del titanio. Esto supuso un resultado sorprendente, ya que con anterioridad a estos hallazgos se creía que era imposible que los metales se integrasen directamente en el hueso.

Como consecuencia de todo ello y tras una serie de trabajos que se extendieron durante más de una década, el profesor Branemark desarrolló un nuevo concepto, llamado osteointegración, que predecía el éxito funcional de los implantes dentales de titanio a largo plazo por medio del contacto íntimo entre el hueso y la superficie del implante. 
Estos estudios revelaban la íntima conexión circulatoria entre la médula ósea y el hueso cortical. Posteriormente se realizaron estudios en perros, observando una capacidad de unión del titanio al hueso de hasta $100 \mathrm{~kg}$ en la mandíbula inferior y de 30 a $50 \mathrm{~kg}$ en la superior.

“Bränemark en 1985 describe la osteointegración como una conexión directa, estructural y funcional entre el hueso vivo y la superficie de un implante sin intervención de tejido blando”.

Según el profesor Branemark los requisitos para conseguir una osteointegración son: implante de material biocompatible, un diseño que lo estabilice mecánicamente con el hueso, condición adecuada del lecho implantario, protocolo quirúrgico que reduzca el daño del hueso y fase de curación sin carga.

Para generar oseointegración, se debe preparar el hueso de tal manera que se produzca la mínima lesión tisular posible, extrayendo la menor cantidad de hueso y sin cambiar la topografía básica de la región. Con la aparición de nuevos materiales en la fabricación de implantes se modifica el concepto de oseointegración, siendo redefinido por Zarb en 1991 como un proceso por el cual se consigue una fijación rígida, asintomática, de materiales aloplásticos y que se mantiene en el hueso durante la carga funcional. (10)

\section{Fibrointegración}

Es la formación de tejido fibroso entre el hueso y el implante. Se produce tras la preparación ósea traumática, necrosis térmica, falta de estabilidad primaria o carga prematura del implante. Un número significativo de implantes roscados desarrollarán tejido blando entre el hueso y el implante (fibrointegración), formando un seudoligamento que conducirá al fracaso de éste. La formación de tejido conjuntivo (fibrointegración) en la interfase puede ser debida a estas situaciones: 
a) Migración apical del epitelio en la interfase, seguido por elementos de tejido conjuntivo.

b) El implante se coloca con demasiada presión.

c) Defectos en la técnica de colocación de implantes.

\section{FACTORES QUE AFECTAN A LA OSEOINTEGRACIÓN}

Son seis los factores esenciales, ampliamente aceptados, para conseguir una buena oseointegración. Fueron propuestos por Albrektsson y col. en 1981 y constituyen la base de la buena práctica clínica en la implantología dental:

El material del implante; la calidad superficial del implante; el diseño macroscópico y dimensional del implante; el estado del hueso receptor; la técnica quirúrgica; las condiciones de carga del implante. Los tres últimos, estado del hueso receptor, técnica quirúrgica y condiciones de carga del implante, son factores propios del control del clínico. Mientras que el diseño, el material y la calidad superficial del implante dental son factores en los que la ingeniería tiene una influencia significativa. No obstante, en la investigación y el desarrollo de los implantes dentales, es fundamental el conocimiento multidisciplinario de todos los profesionales implicados.

\section{Materiales bioinertes y bioactivos}

Un biomaterial es un material no vivo utilizado y concebido para interactuar con el sistema biológico. Así pues, el material con el que se fabrique el implante dental es un biomaterial. No obstante, el biomaterial elegido para su fabricación deberá satisfacer las diferentes propiedades requeridas para su buen comportamiento a corto y largo plazo, tales como biocompatibilidad, la resistencia mecánica, la resistencia a la degradación, la disponibilidad, etc. 
En cualquier caso, el concepto más importante es que el material debe ser biocompatible. Esto significa que la presencia del biomaterial dentro de los tejidos biológicos provoca respuestas bioquímicas que no son perjudiciales a los tejidos ni interfieren en el buen desempeño de las funciones sustitutorias o de reparación del biomaterial. Se define como la capacidad de ser utilizado en una aplicación específica con una respuesta adecuada del tejido receptor.

El material bioinerte durante su vida en servicio no cede ninguna substancia en cantidades perjudiciales, por lo que no provoca reacciones adversas en el tejido.

El titanio comercialmente puro es generalmente aceptado como un material bioinerte y, las leves reacciones que provoca en el medio biológico y sus adecuadas propiedades mecánicas, son los factores determinantes para que sea el material por excelencia en la selección para la fabricación de los implantes dentales. A este respecto, cabe decir que su magnífica respuesta en el tejido a corto y a largo plazo es debida a las propiedades específicas de su superficie y, es por ello, que los avances más significativos en la mejora de dicha respuesta se están consiguiendo controlando las distintas propiedades asociadas a la calidad de la superficie del implante dental.

El material bioactivo causa reacciones tisulares favorables, lo que lleva al establecimiento de enlaces químicos directos con los tejidos circundantes. Un ejemplo es la hidroxiapatita (HA) es un material bioactivo para el tejido óseo debido a que es la fase mineral del hueso. Este hecho hace que las células la "reconozcan" como un material biológicamente no ajeno, esto lleva a la unión química entre ella y el tejido ordenado. Su principal inconveniente son sus propiedades mecánicas ya que es un material excesivamente frágil. Por esta razón, en la implantología dental, sólo se emplea como recubrimiento sobre el metal. De esta manera, se intenta combinar la bioactividad de la HA con las excelentes propiedades mecánicas del titanio. 
Quizás, el mayor problema que presenta este tipo de implantes es que la HA se aplica sobre el titanio comercialmente puro por medio de un tratamiento de proyección por plasma. Esto conlleva, en determinadas ocasiones, que los implantes fallen por degradación de la capa, por desprendimiento de la misma, o porque parte de ella quede embebida, con el paso del tiempo, en la matriz ósea.

\section{El titanio en la Implantología.}

El titanio es el noveno elemento más abundante en la corteza terrestre y se obtiene a partir de minerales ricos en óxido de titanio ( $\mathrm{TiO} 2)$ como son el rutilo y la ilmenita. Se descubrió en 1794, pero no se pudo separar del mineral de forma eficiente hasta el 1936 debido a su altísima afinidad por el oxígeno. (9) Fue finalmente Kroll quien desarrolló la metodología de obtención que lleva su mismo nombre, y desde entonces el titanio se ha empleado en un número creciente de aplicaciones, entre ellas las biomédicas. Así, las técnicas modernas de extracción y refinado permiten la obtención de grandes cantidades del metal para la producción de diferentes grados comerciales de titanio. Las normas internacionales determinan cuatro grados de titanio comercialmente puro para su aplicación médica. Los distintos grados se clasifican en función de la cantidad de elementos adicionales minoritarios que contiene cada aleación de titanio comercialmente puro (Tabla 1.). De esta manera, a medida que aumenta el grado (desde el I hasta el IV) aumenta la cantidad de elementos agregados y, con ello, como propiedades más significativas, aumenta la resistencia mecánica y la resistencia a la corrosión. 
Víctor H. Silva-Miranda; Patricia P. Astudillo-Campos; María V. Vélez-Sánchez

\begin{tabular}{lllllll}
\hline & $\mathbf{N}$ & $\mathrm{C}$ & $\mathrm{H}$ & $\mathrm{Fe}$ & $\mathrm{O}$ & $\mathrm{RT}(\mathrm{Mpa})$ \\
\hline Grado I & 0.03 & 0.10 & 0.015 & 0.20 & 0.18 & 235 \\
Grado II & 0.03 & 0.10 & 0.015 & 0.30 & 0.25 & 338 \\
Grado & 0.05 & 0.10 & 0.015 & 0.30 & 0.35 & 441 \\
III & & & & & & \\
Grado IV & 0.05 & 0.10 & 0.015 & 0.50 & 0.40 & 540 \\
Ti 6AI & 0.05 & 0.08 & 0.012 & 0.25 & 0.13 & 880 \\
4V & & & & & & \\
\hline
\end{tabular}

\section{Tabla 1. Elias C. N Tratamiento de superficies para mejorar la oseointegración. Quitessense; 2009}

El factor fundamental que hace que el titanio comercialmente puro sea el material elegido para la fabricación del implante dental es que con él es posible alcanzar la oseointegración. Ello está directamente vinculado con su excelente biocompatibilidad, la cual a su vez se relaciona con sus adecuadas propiedades mecánicas y alta resistencia a la corrosión. A continuación, se repasan todos estos factores.

\section{Biocompatibilidad y oseointegración}

Biocompatibilidad es la capacidad de un material de ser utilizado en una aplicación específica con una respuesta adecuada del tejido receptor. Esta definición implica la interacción entre un huésped, el material y la función esperada del material.

\section{Biocompatibilidad del titanio y su influencia en la oseointegración}

El Titanio comercialmente puro es un caso especial, ya que cuando se implanta en tejido duro, el hueso es capaz de crecer ordenado en contacto directo con el implante, sin una apreciable cápsula de tejido blando a su alrededor. No obstante, el implante no está adherido al hueso, ya que a nivel ultra estructural se aprecia una capa biológica de tejido blando de unos escasos 5-10 nm de 
grosor que, en el mejor de los casos, separan al implante del hueso (31). Por este motivo se le considera un material con excelente biocompatibilidad, lo cual le permite llevar a cabo su función de anclaje protésico, a largo plazo, de manera óptima. Es decir, su alta biocompatibilidad en hueso es lo que ha permitido el desarrollo de la oseointegración y, por lo tanto, su utilización masiva en la implantología dental.

Es pues, el titanio comercialmente puro es lo que se conoce como un material bioinerte lo que provoca su alta biocompatibilidad y su capacidad para la oseointegración. Hay algunos autores que lo sitúan también como un material bioactivo, por el hecho que es capaz de generar la respuesta fenotípica del osteoblasto cuando éste está sobre su superficie o porque es capaz por sí mismo de absorber calcio y fósforo en su superficie, lo que permite la creación de un compuesto de fosfato de calcio de tipo cementante, (13) que aprovecharán las células para expresar su fenotipo.

En cualquier caso, la creación de la capa colaginosa, aunque muy fina, parece ser un hecho incuestionable. La mayoría de los autores coinciden en señalar a la alta resistencia a la corrosión por lo que resulta ser altamente bioinerte en los tejidos y lo que permite su magnífica oseointegración. “cuanto menor sea la cantidad de residuos cedidos por el material al medio biológico, mayor será el contacto entre el tejido y el biomaterial". Es incuestionable que la ausencia de reactividad del titanio comercialmente puro es fundamental en su éxito en la implantología dental. Sin embargo, no debe ser la única explicación, ya que en ese caso, al implantarse en otros tejidos, tendría un comportamiento similar; o por otra parte, cualquier otro material capaz de no ceder productos de su degradación debería expresar la misma respuesta.

Las respuestas a estas incógnitas se deben buscar en los procesos biológicos que están asociados a la curación de los tejidos alrededor del implante. Así, cuando un material es ubicado en el hueso, la primera reacción que se produce después de la no despreciable interacción con los iones 
del medio fisiológico es la absorción no selectiva de un gran número de proteínas. A continuación, los neutrófilos y los macrófagos identifican al implante dental y en función de la conformación, la orientación y el tipo de proteínas absorbidas, los macrófagos interaccionan con la superficie y segregan cierto tipo de citoquinas que son mensajeros biológicos moleculares, que atraen a los fibroblastos produciéndose, en última instancia, la encapsulación del biomaterial con el tejido fibroso. Es pues fundamental el tipo de interacción que se produce entre las proteínas y la superficie del implante, así como con las células que intervienen en los procesos de curación y remodelación del tejido óseo. Ello hará que la respuesta del Titanio comercialmente puro sea superior a la de otros biomateriales. La conclusión, en cualquier caso, es que la superficie del material regula la respuesta biológica y, en última instancia la calidad de la oseointegración. Las propiedades físicas, químicas y topográficas de la superficie intervienen de forma decisiva en los procesos biológicos (interacción proteica y celular) y las distintas tecnologías aplicadas sobre esta superficie, son objeto de continua investigación en busca de favorecer la velocidad y la calidad de la respuesta del tejido óseo.

\section{Propiedades mecánicas del titanio}

Las propiedades mecánicas del titanio comercialmente puro, tales como la elasticidad, la resistencia a la tracción, la resistencia específica y la fatiga, son un claro valor añadido a la calidad superficial del titanio como elección para su uso en la fabricación de los implantes dentales. A pesar de que los valores concretos para el metal dependen del grado comercial elegido, se puede decir que el titanio comercialmente puro posee buenas propiedades mecánicas para su aplicación como implante dental.

El módulo de elasticidad límite $(170 \div 483 \mathrm{MPa})$ y la resistencia a la tracción $(240 \div 550 \mathrm{MPa})$ son valores suficientes para soportar las cargas mecánicas que el implante recibe en boca. Esta elasticidad representa la mitad o menos del que poseen otros metales como el acero inoxidable para 
uso quirúrgico o las aleaciones cromo-cobalto. Este hecho representa una característica importante ya que comparativamente un menor módulo de elasticidad (más cercano al del hueso), disminuye el fenómeno de relajación de tensiones en los tejidos óseos circundantes. Consecuentemente, la remodelación ósea se ve favorecida. Es importante señalar que los valores de resistencia mecánica son fuertemente dependientes del grado comercial del titanio (Tabla 1) y de los procesos de conformado y tratamientos térmicos elegidos para la fabricación del implante, pudiendo variar para el grado 1 entre $240 \mathrm{MPa}$, y 540MPa para el grado 4. En este sentido, el implante dental se obtiene por mecanizado de barras de Titanio comercialmente puro de grados II, III o IV en estado recocido que, a pesar de tener menor resistencia mecánica, facilita las operaciones de mecanizado.

Finalmente, la resistencia a la fatiga mecánica es un factor crítico en la vida en servicio del implante ya que éste debe soportar cargas cíclicas de carácter flexión-torsión que, en último caso, llevarán a su rotura por medio de la degradación mecánica, de hecho, los implantes fracasados por rotura están asociados a este tipo de fallo mecánico. No obstante, el número de implantes que rompen por fatiga mecánica es muy escaso, representando un porcentaje inferior al $0.2 \%$ de todos los implantes que fracasan en boca.

\section{Resistencia a la corrosión}

El titanio es un material altamente reactivo, siendo fácilmente oxidable por diferentes medios. La cinética de oxidación es extremadamente alta, de manera que los primeros eventos asociados a la oxidación se producen en una escala de tiempo de unos pocos nanosegundos. Debido a esta alta reactividad y la alta velocidad de los procesos asociados a la oxidación, está siempre recubierto de una capa de óxido, en la mayoría de los casos, la capa superficial oxidada está compuesta por el más estable de todos los óxidos de titanio, es decir, el dióxido de titanio (TiO2). 
Al contrario que el titanio, el $\mathrm{TiO} 2$ es un compuesto estable, altamente resistente a los ataques químicos de la mayoría de substancias. La excelente resistencia química y a la corrosión es debida a la presencia en su superficie de este dióxido químicamente estable. (30) El óxido se distribuye en una densa película de entre 5-10 nm que protege al metal de los ataques químicos, incluyendo el de los agresivos fluidos corporales. Este factor no se debe confundir con que sea químicamente inerte. De hecho, las superficies de $\mathrm{TiO} 2$ reaccionan en soluciones acuosas y absorben y disocian moléculas orgánicas, actuando en muchos casos, como catalizadoras de un gran número de reacciones químicas. Esta capa de dióxido, asimismo, actúa como barrera protectora para evitar la emisión de cualquier tipo de ion desde el interior del metal hacia el medio fisiológico.

Todo ello hace que sea un metal tan resistente a la corrosión aún en contacto con los fluidos corporales, este hecho tiene consecuencias directas en su excelente biocompatibilidad.

\section{Tensiones residuales}

Es de especial importancia el hecho de que los primeros eventos que se producen tras la implantación (contacto con la sangre, absorción de proteínas y otras moléculas biológicas, adhesión celular, etc.) son debidos a la interacción entre el ambiente biológico y la superficie del material sintético. Asi mismo, la respuesta de las reacciones biológicas y los caminos particulares que eligen las células y como consecuencia, la secuencia de eventos que llevan a una mejor o peor oseointegración, dependen en fuerte medida de una serie de propiedades relacionadas con la superficie del implante. Sin embargo, todavía no es conocido con profundidad cual o cuales de estos factores son los de mayor relevancia clínica; y cómo influyen sobre la respuesta del organismo. Las propiedades de una superficie que, potencialmente, pueden modificar el comportamiento biológico del material son variadas. Estas propiedades nos permiten definir exhaustivamente la calidad de la 
superficie después de los cambios que se operan sobre ella en función de los procesos de fabricación o del tiempo de exposición al medio biológico.

A continuación, se detallan las características más importantes de las propiedades fisicoquímicas y topográficas de la superficie del titanio para su uso en implantología.

\section{Propiedades fisicoquímicas}

El conocimiento de las propiedades fisicoquímicas del titanio comercialmente puro supone el estudio exhaustivo de las propiedades de la capa de óxido de titanio que crece sobre él de manera natural y espontáneamente en contacto con el aire y otros medios. Esta capa protege al metal contra el aumento incontrolado de su oxidación, las reacciones químicas y biológicas indeseables, y la corrosión. Como consecuencia, los agentes químicos y biológicos no interaccionan directamente con el metal, sino con esta capa estable de óxido.

Se pueden identificar una serie de diferentes óxidos de titanio sobre la superficie (Ti3O, Ti2O, Ti3O2, TiO, Ti2O3, Ti3O5y TiO2). El más estable de ellos es el Dióxido de Titanio (TiO2), con el titanio en su estado de oxidación grado IV.

Del análisis que de todas estas propiedades se puede concluir que:

1.- La naturaleza altamente protectora de la capa de óxido, que generalmente sólo tiene unos pocos nanómetros de grosor, es consecuencia de su integridad natural y su estabilidad química en un amplio rango de $\mathrm{pH}$, electrolitos y fluidos corporales.

2.- El óxido de titanio superficial se repasiva rápidamente después de una pérdida local, como por ejemplo por efecto del desgaste mecánico. 
3.- La baja solubilidad de los óxidos de titanio hidratados, junto con la menor tendencia a formar compuestos de titanio cargados, son aspectos muy relevantes para la biocompatibilidad del titanio.

4.- Se puede asumir una cierta semejanza fisicoquímica entre la superficie limpia del óxido de titanio y el agua como consecuencia de la extensiva hidroxilación/hidratación y su moderada hidrofilia. Esto conlleva una interacción de la superficie como las proteínas.

5.- La "habilidad natural" a formar capas de calcio-carbonato-fosfato en la superficie del óxido de titanio a través de procesos específicos de intercambio químico con los constituyentes de los fluidos corporales (sangre, fluido intersticial), genera, después de algún tiempo in vivo, la modificación de la interfaz material sintético/material biológico, por formación de una capa de unos pocos nanómetros de grosor.

\section{Propiedades topográficas}

La topografía superficial (rugosidad y textura) puede considerarse la más importante de las propiedades superficiales que influyen en la respuesta del organismo a la presencia del implante. Es reconocido que, por ejemplo, aumentar la rugosidad por encima de la obtenida al ser mecanizado, el implante dental mejora la respuesta osteoblástica. De hecho, las superficies de los implantes, en la mayoría de los casos, poseen topografías superficiales especialmente diseñadas y fabricadas atendiendo al conocimiento expreso de que los detalles topográficos, tanto a escala micrométrica como nanométrica, supone un factor de calidad relevante. 
Tipos de superficie en los implantes dentales

Implantes con superficie sin tratamiento (Lisa o Usinada)

Los implantes con superficie sin tratamiento lo de superficie lisa, fueron utilizados desde los inicios de la implantología hasta el final de la década de los años 90. Después de su fabricación estos implantes son sometidos a limpieza, descontaminación y esterilización, son llamados inadecuadamente implantes lisos o pulidos, pues al ser observados bajo el microscopio se observa que las superficies de estos implantes presentan surcos, rayas o marcas hechas por las herramientas de corte en su fabricación. La desventaja de los implantes sin tratamiento de superficie se debe al hecho que los osteoblastos tienen afinidad a las rugosidades, con la tendencia a crecer en dirección a los surcos que existen en la superficie. (Foto 1 y 2) Esta característica exige a estos implantes un mayor tiempo de espera a la oseointegración y poder someter a carga protésica, tal como lo sugirió Branemark de hasta seis meses. 

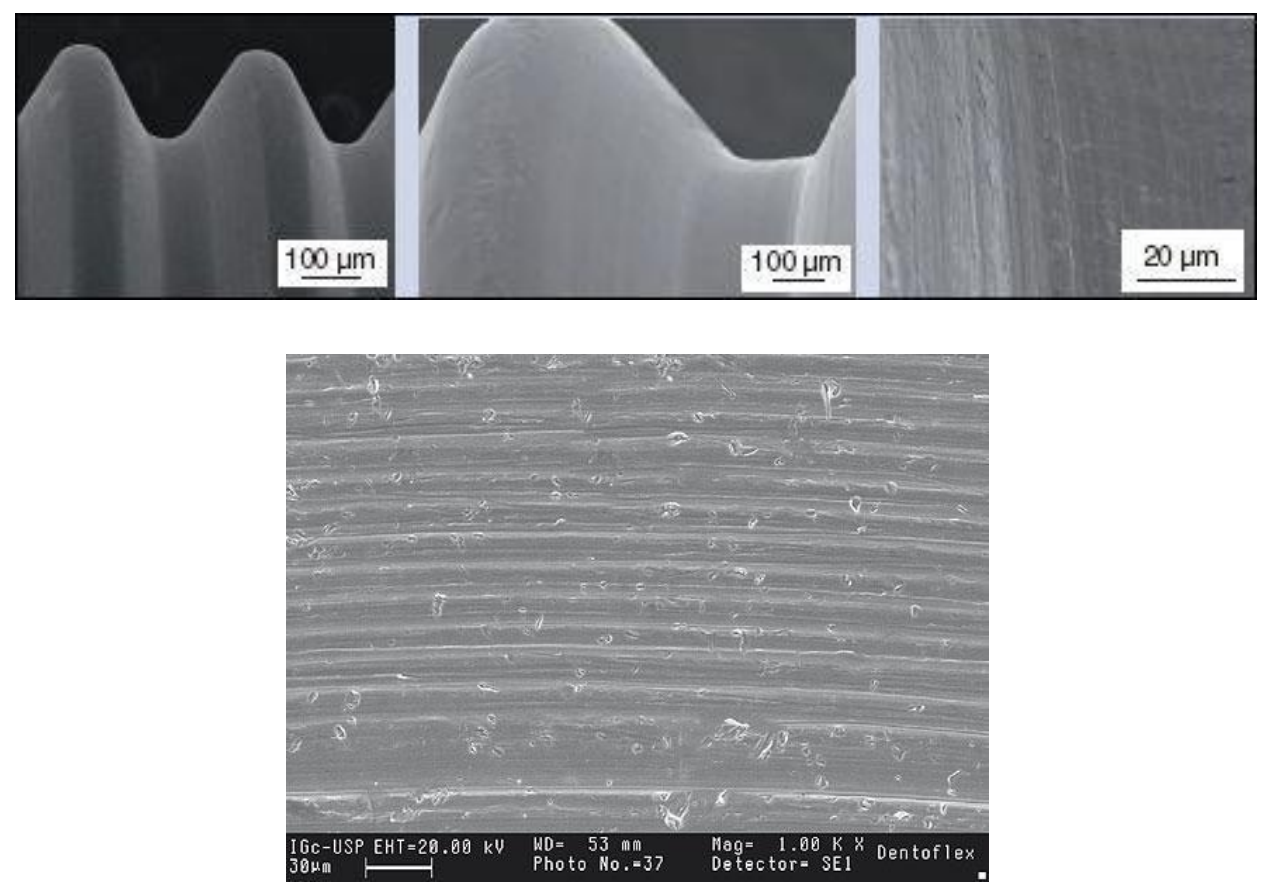

Foto 1.-Prof. Elías C. M; Microfotografía, muestra las marcas dejadas en la superficie del implante dejadas por las herramientas de corte en su fabricación. Tratamentos das superfícies dos implantes para melhorar a qualidade e a osseointegração (Visão contemporânea da implantodontia. 1 ed. São Paulo: Quitessense Editora Ltda, 2009, v. 1, p. 1-20.)
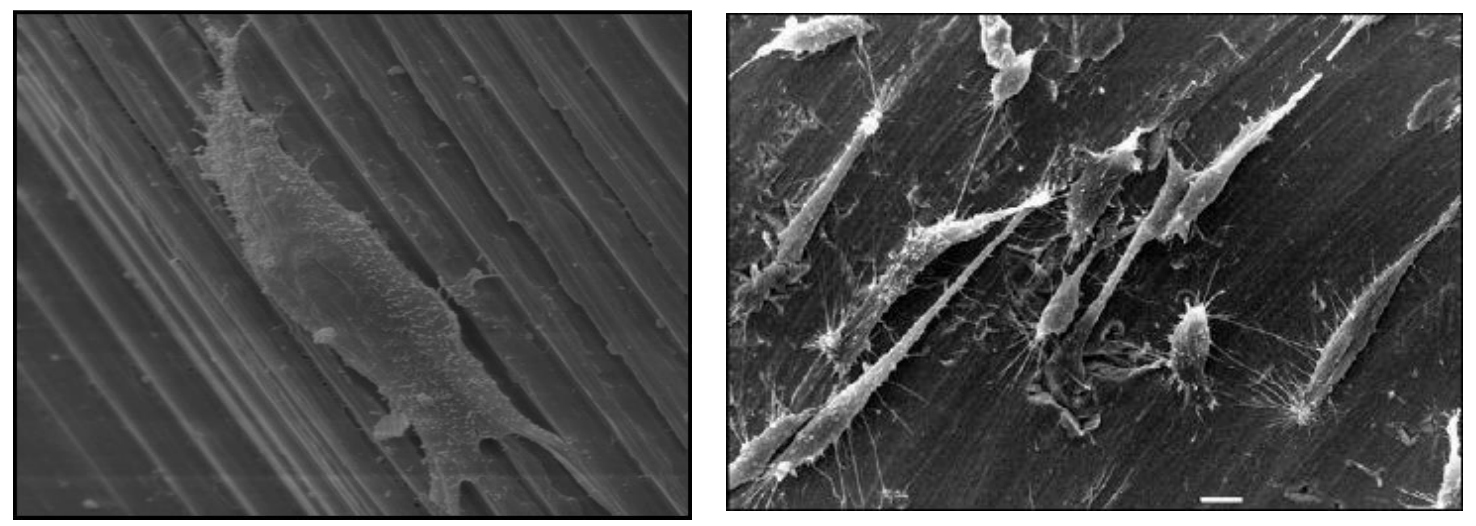

Foto 2.- Microfotografía muestra el adosamiento del osteoblasto en dirección de las marcas creadas en la fabricación del implante. Prof. Elías C. M; Tratamentos das superfícies dos implantes para melhorar a qualidade e a osseointegração (Visão contemporânea da implantodontia. 1 ed. São Paulo: Quitessense Editora Ltda, 2009, v. 1, p. 1-20.) 
Son muchos los tratamientos que se han aplicado sobre el titanio comercialmente puro y su descripción se puede abordar desde distintos puntos de vista. En función del efecto que persiguen:

a) la limpieza de la superficie y/o la eliminación de la capa superficial nativa;

b) la modificación de la estructura y la topografía (lisa, rugosa, porosa); y

c) la modificación de la composición y la estructura de la capa de óxido, cambiando el carácter bioinerte del titanio por un material bioactivo.

Los tratamientos más significativos, por ser los más empleados al haber obtenido unos mejores resultados de comportamiento biológico, mecánico, y contra la degradación, para cada uno de los grupos, son: el pulido y la limpieza con disolventes, en el primer caso; el granallado, el ataque ácido y la proyección por plasma de titanio, en el caso de la modificación topográfica; y el ataque alcalino y la proyección por plasma de fosfatos de calcio, para el caso de la modificación de la naturaleza química de la superficie.

Otra clasificación posible, y también muy útil para la descripción de los distintos tratamientos, es la que toma como base el carácter fisicoquímico fundamental del tratamiento empleado:

1.- Métodos mecánicos: desbaste, pulido, mecanizado, y granallado.

2. Métodos químicos: limpieza con disolvente, ataque ácido, ataque alcalino, pasivado, anodizado, electro pulido.

3.- Métodos al vacío: descarga lumínica, descarga eléctrica, implantación iónica.

4.- Métodos de recubrimiento o por adhesión: proyección por plasma, sol-gel, "magnetrón sputtering”, ablación láser. 
5.- Métodos bioquímicos: enlace de iones y/o moléculas activas por adsorción físicoquímica, por enlace covalente con o sin espaciador, y por inclusión en materiales que actúan de portadores.

\section{Implantes con Granallado o Jateado de la superficie}

Para mejorar la respuesta celular e interacción del implante con los tejidos biológicos la principal estrategia seguida es la obtención de superficies rugosa. (Foto 3) Los primeros estudios clínicos de Predeckiy col. (24) obtuvieron resultados que motivaron un gran número de investigaciones sobre la relación entre rugosidad y curación del tejido óseo. En la actualidad, está ampliamente aceptado que la rugosidad superficial de un implante es un factor determinante. Los cambios topográficos de la superficie tienen influencia significativa en la cascada de eventos que llevan a la aceptación del implante por el hueso receptor, desde la absorción de proteínas hasta la mineralización de la matriz extracelular del tejido óseo, pasando por la adhesión, proliferación y diferenciación, tanto de los osteoblastos como de los osteoclastos.

Todo ello conlleva una mayor rapidez en los procesos de curación y, por lo tanto, una más rápida y biológicamente eficaz oseointegración.

Asi mismo, la micromovilidad entre el hueso y el implante impide la curación del hueso y, de hecho, promueve la lisis del tejido. La interdigitación del tejido óseo con una apropiada topografía superficial reduce de forma efectiva esta minimovilidad, este factor promueve la curación del hueso en contacto directo con el implante y, como consecuencia, mejora la fijación inicial y a largo plazo del mismo.

En el caso concreto de los implantes dentales, ya se han realizado un número considerable de estudios de caracterización de la rugosidad, actualmente, hay suficiente evidencia para considerar 
que, comparados con implantes pulidos o mecanizados, los implantes dentales con microrugosidades mejoran la oseointegración, ya que:

1.- alcanzan de manera más rápida la oseointegración.

2.- muestran mayores porcentajes de hueso en contacto directo con el implante, y

3.- aumentan la resistencia al aflojamiento, puesto que se necesitan fuerzas de torsión superiores para su extracción.

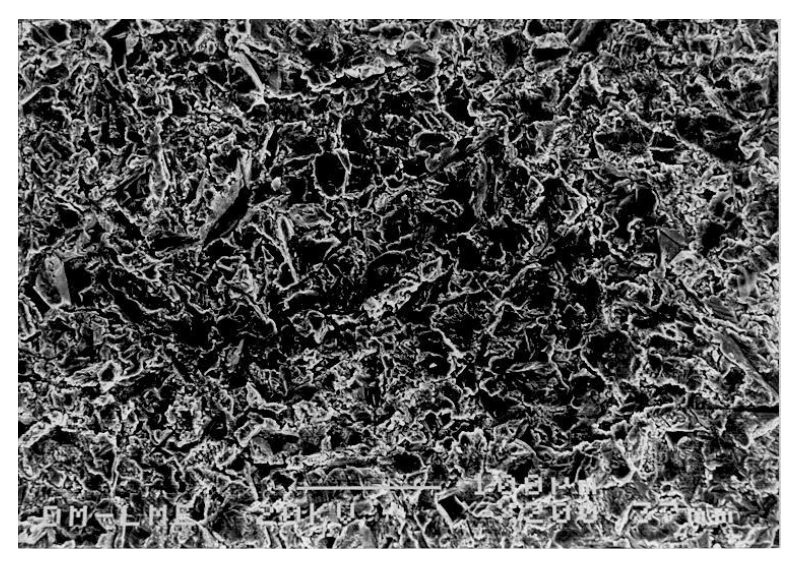

Foto 3.- Conrado A. D. Tesis UPC; Micrografía, muestra superficie con tratamiento de granallado con partículas de AL2. (Capt \#5 pag: 257 (2004). 


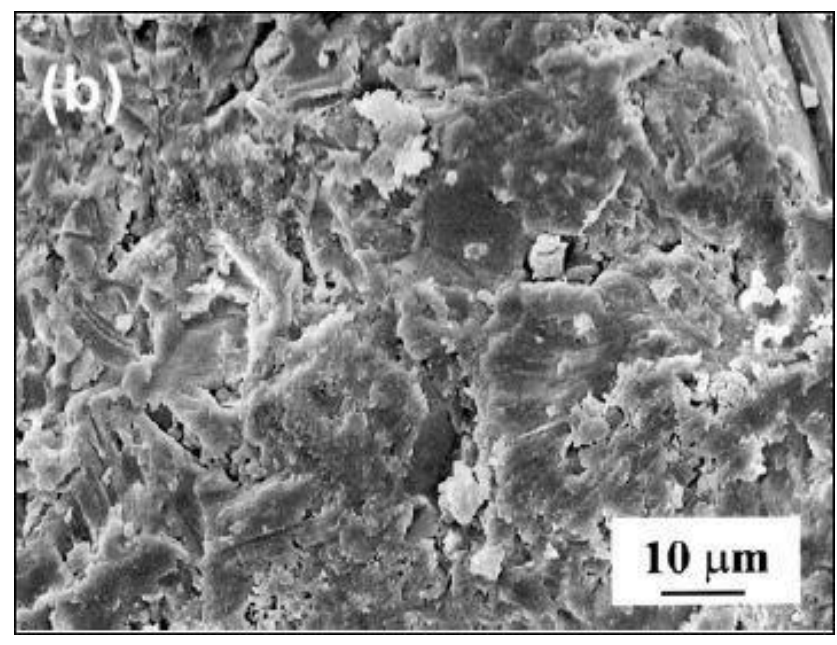

Foto 3.- Muestra superficie con tratamiento de granallado con partículas de AL2. Conrado A.

\section{Tesis UPC; Micrografía; Capt \#5 pag: 257 (2004)}

\section{Variables en el Granallado}

El método se basa en bombardear la superficie del material con partículas duras abrasivas a gran velocidad. Estas partículas se pueden enviar en seco o embebidas en un líquido. Cuando las partículas impactan en la superficie provoca micro sustracción del material y deformación plástica localizada, logrando hacer rugosa la superficie, e inducir una capa superficial de tensiones residuales de compresión.

Cuando el granallado o jateado se controla específicamente, esta capa de tensiones residuales de compresión es de grosor y magnitud controlable y las propiedades mecánicas de fatiga y corrosiónfatiga del implante se pueden mejorar significativa y controladamente. 


\section{Tamaño de la Partícula}

Esta es la variable más importante para el control de la rugosidad final de una superficie jateada o granallada, de tal manera que a medida que aumenta el tamaño de la partícula de proyección, aumenta la rugosidad.

Teniendo en cuenta el amplio intervalo de tamaños de partículas de los que se puede disponer (entre 3 y $5600 \mu \mathrm{m}$ ), de esta manera, sobre el titanio y sus aleaciones para aplicaciones biomédicas se han estudiado tamaños de partículas desde unos pocos micrómetros y que dejan rugosidades inferiores a $\mathrm{Ra}=0,1 \mu \mathrm{m}$ o mayores, de entre 200 y $600 \mu \mathrm{m}$, para rugosidades $\mathrm{Ra}=2-6 \mu \mathrm{m}(\mathrm{Ra}=\mathrm{rugosidad}$ aritmética)

Los estudios de Wennerberg muestran un trabajo de tratamiento de granallado como único tratamiento de superficie, dando un valor de rugosidad óptima. Este valor óptimo se estableció en Ra $=1,5 \mu \mathrm{m}$, de acuerdo a sus resultados de histomorfometría en fémures de conejos.

\section{Naturaleza de la Partícula}

La segunda variable importante a considerar es la naturaleza de las partículas. Debido a la alta energía en el impacto, algunas de las partículas se rompen y partes de ellas quedan incrustadas en la superficie del implante sin posibilidad de ser removidas. (Foto 4)

En consecuencia, la naturaleza de las partículas utilizadas para realizar el granallado debe ser suficientemente estable químicamente para que sean inertes en el medio biológico y, por lo tanto, biocompatibles.

Por otra parte, la heterogeneidad química que se genera en la superficie del implante puede comprometer las excelentes propiedades de resistencia a la corrosión que tiene el titanio 
comercialmente puro en el medio fisiológico. Las partículas más utilizadas para el granallado de implantes dentales son la alúmina (A12O3) y la sílice como carburo de cilicio ( $\mathrm{SiC})$, es decir, óxidos inertes y abrasivos.

En cualquier caso, parece razonable pensar que una vía para evitar los posibles problemas asociados a la inevitable presencia de las partículas sobre las superficies granalladas es utilizar partículas de proyección de óxido de titanio. El titanio se recubre espontáneamente de este óxido, por lo que su utilización evitaría la heterogeneidad química de las superficies granalladas.

Teniendo en cuenta todas estas premisas, las naturalezas de partículas utilizadas son:

1.- Oxido de aluminio. Alúmina (A12O3). Este material es el más empleado y estudiado, sin embargo, se le cuestiona, por sus posibles relaciones con enfermedades pulmonares, óseas y cerebrales. Por la posibilidad de transferir aluminio al organismo, situación aún no determinada.

2.- Carburo de silicio (SiC). Estas partículas se seleccionaron por dos motivos. En primer lugar, igual que la alúmina, es muy utilizado en la industria del abrasivo para fabricar herramientas flexibles de corte rápido, y su precio es bajo, aunque mayor que el del óxido de aluminio. Además, es también un material cerámico que tiene una alta biocompatibilidad.

La segunda razón por la que se ha seleccionado el SiC está relacionada con su capacidad para reaccionar con el ácido fluorhídrico. Este hecho se pretende aprovechar para realizar el pasivado de la superficie granallada con una mezcla de $\mathrm{HF} / \mathrm{HNO}$; en lugar de utilizar el pasivado convencional con $\mathrm{HCl}$. De esta forma se puede producir la reacción a temperatura ambiente:

Con este tratamiento se pretende que las partículas de $\mathrm{SiC}$ reaccionen con el ácido durante el pasivado, produciendo un efecto de limpieza superior en el material granallado. 


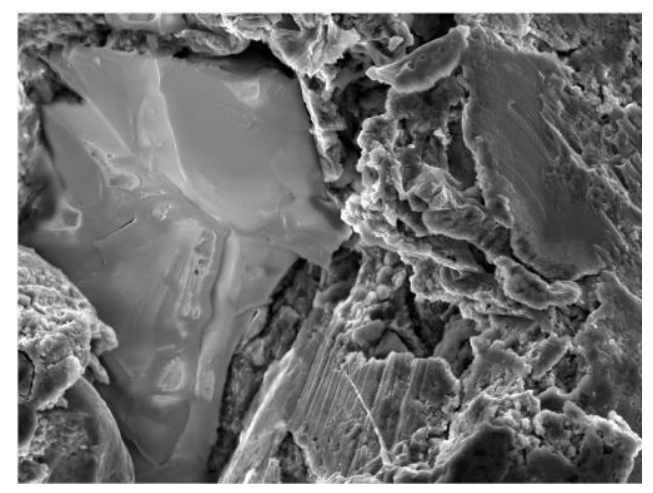

Foto 4.- Microfotografía en la que se aprecia una partícula de $\mathrm{Al}_{2} \mathrm{O}_{3}$ incrustada sobre la superficie del metal granallado. Conrado A. D. Tesis UPC; Micrografía; Capt \#5 pag: 257 (2004)
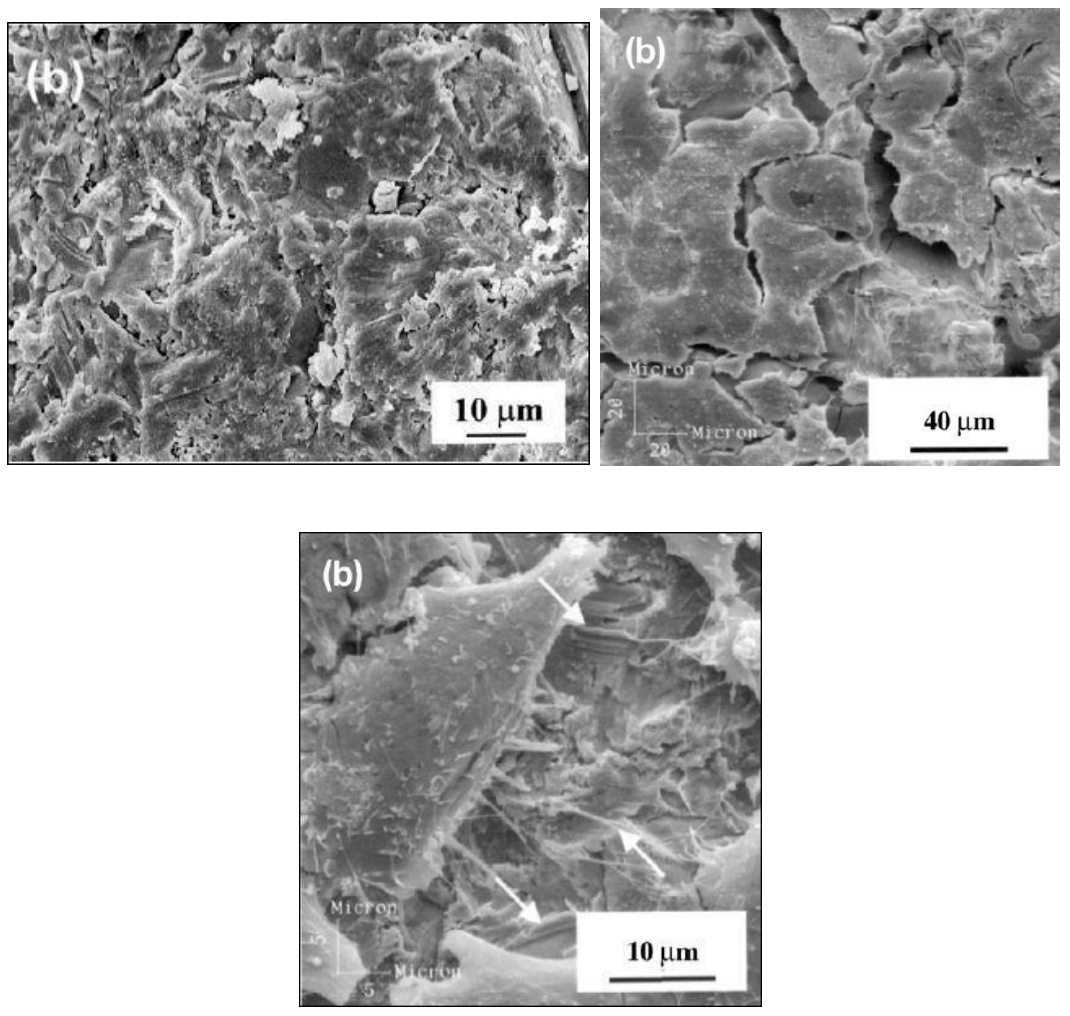

Marcelo H. Carlos N. Elias: Micrifotografía que muestra la adhesión del osteoblasto en superficie granallada con $\mathrm{Al}_{2} \mathrm{O}_{3}$. 


\section{Implantes con Superficies Tratadas con ácidos}

El acondicionamiento de la superficie de los implantes con ácidos, es una mejora importante en conseguir aumentar aún más el área de contacto de un implante ya granallado, cada empresa se reserva una metodología de tratamiento en lo concerniente a la concentración tipo de ácidos utilizados, tiempo y temperatura de exposición etc. Como información general, el tratamiento con ácidos se realiza por inmersión de los implantes en baños de soluciones ácidas conteniendo ácido clorhídrico en asociación con ácido sulfúrico, o ácido fluorhídrico más ácido nítrico, por un periodo de tiempo que va en aproximadamente 30 minutos, con esto se consigue homogenizar las rugosidades que se consiguieron con el granallado y disolver las partículas abrasivas con las que se hace dicho granallado y que inevitablemente quedan atrapadas en el cuerpo del implante, luego son lavados y sometidos nuevamente a una inmersión acuosa de $\mathrm{HNO}_{3}$ obtener un pasivado del óxido de titanio y conseguir una cama de óxido estable. (Foto 5) Elías 2003
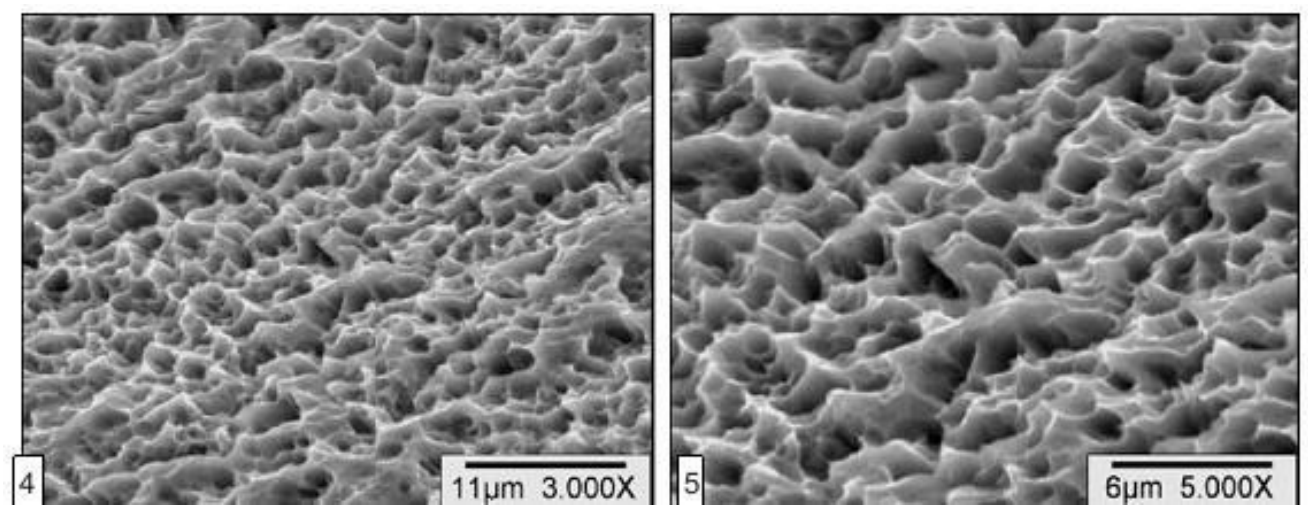

Foto 5.- Microfotografía muestra una superficie tratada con ácidos $\mathrm{HCL}+\mathrm{HNO}_{3}$ 


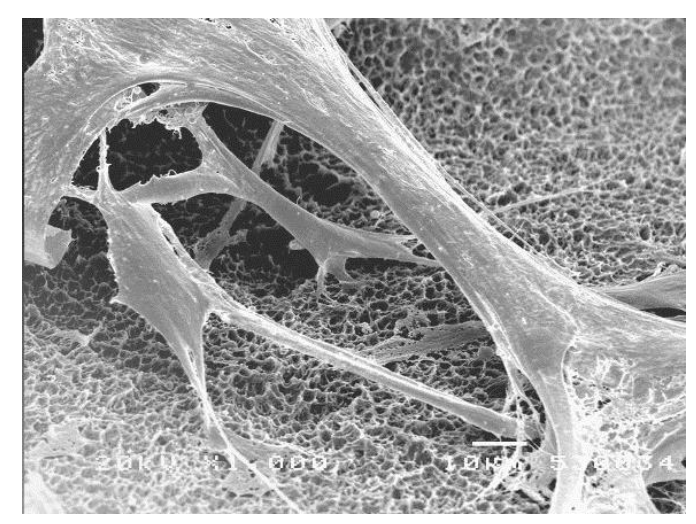

\section{Respuesta del Osteblasto en superficie tratada con ácidos}

\section{Pasivado}

Consiste lavar en ultrasonidos con jabón durante 10 min y secar con aire forzado, luego son atacados químicamente en una disolución de ácido clorhídrico $(\mathrm{HCl})$ durante 30 segundos o con una disolución de ácido fluorhídrico (2\%) y ácido nítrico (10\%) durante 30 segundos finalmente, se lava en ultrasonidos con jabón durante 10 min y se seca con aire forzado. El Pasivado busca reforzar la capa de óxido para evitar la liberación de iones metálicos, así también, aumentar el espesor de esta muy delgada capa de óxido y aumentar la resistencia a la corrosión, aumentando la biocompatibilidad del implante.

\section{Humectabilidad}

El ángulo de contacto de un líquido con una superficie es una forma de cuantificar la energía superficial de los sólidos o la capacidad que tiene los líquidos de mojar el sólido, es así como determinan cuan hidrofilica es una superficie. Si el ángulo de contacto de la gota al ser colocada sobre una superficie es superior a $90^{\circ}$ se considera que la superficie es hidrofobica. Al entrar en contacto una gota con la superficie de un sólido existe una interacción entre los átomos del líquido y del sólido, esta interacción se interpreta como fuerza de atracción entre sus átomos, cuanto mayor es 
esta interacción o fuerza de atracción molecular, mejor es la humectación del líquido sobre el sólido. (Fotos 6, 7, 8)

Estudios realizados por Baier y Meyer, relacionan la tensión superficial de los implantes dentales como una variable crítica en la biocompatibilidad. Materiales con alta energía libre superficial, se absorben más fácilmente las macromoléculas y poseen mayor número de sitios favorables para permitir la adhesión de las células dando mejores resultados en la oseointegración.

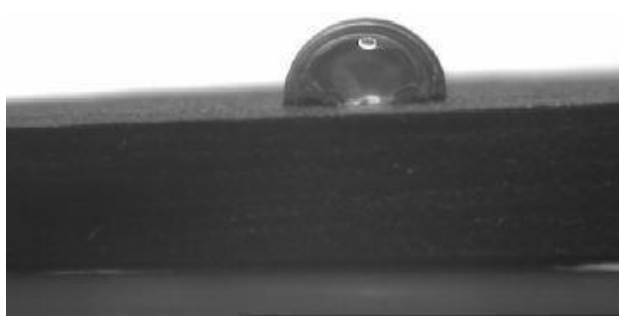

Foto 6.- Estudio de humectabilidad U. de Granada; la fotografía muestra el ángulo de contacto en superficie lisa

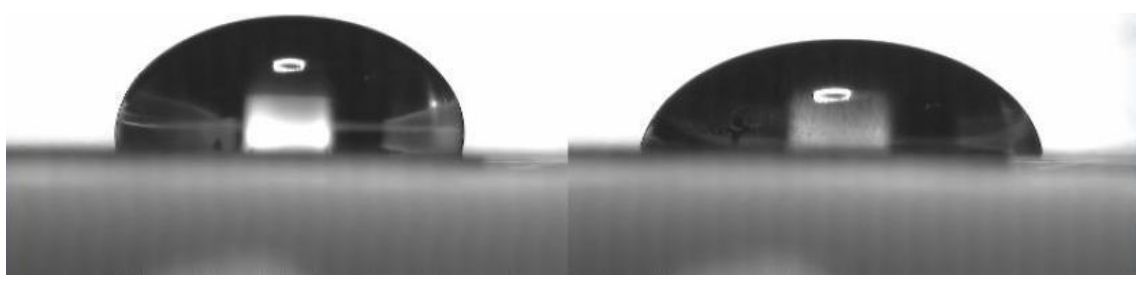

Foto 7.- Estudio de humectabilidad U. de Granada; la fotografía muestra el ángulo de contacto en superficie lisa y arenada o jateada.

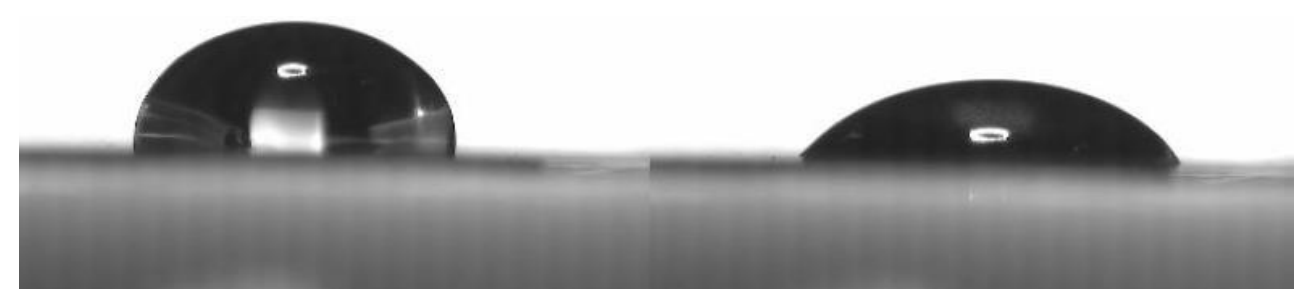

Foto 8.- Estudio de humectabilidad U. de Granada; la fotografía muestra el ángulo de contacto en superficie arenada y arenada + grabada. 


\section{Implantes con Superficies Bioactivas}

Es bien conocido que la evolución de un implante maquinado a la texturización y preparado de la superficie se ha consiguiendo superficies rugosas, porosas con estabilidad en la camada de óxido y una buena energía superficial esto hace que un implante sea eficaz en conseguir una mejor estabilidad inicial y una mejor respuesta osteoblástica, consiguiendo una estabilidad superior a largo plazo.

Con el objetivo de mejorar aún más la oseointegración y sobre todo en su fase inicial después de la instalación del implante, las innovaciones y estudios se basan en aportar al implante materiales que son considerados bioactivos.

\section{Hidroxiapatita por Proyección de Plasma}

En esta técnica la hidroxiapatita en forma de polvo es fundida y llevada al estado de plasma al ser calentadas a temperaturas superiores a los 10000 grados con lo que la cerámica se descompone parcialmente, en este estado es impactada a velocidades de $400 \mathrm{~m} / \mathrm{s}$ contra la superficie fría del implante esto hace que se una al titanio por interacción mecánica entre el sustrato y la cerámica, al enfriarse esta rápidamente. Todo ello trae una serie de inconvenientes como la dificultad del control de la composición, la cristalinidad del recubrimiento, esta unión deja bolsas de aire entre capas, etc. (Foto 9) Esta unión de carácter mecánico hace que estos recubrimientos, además de degradarse bioquímicamente sean susceptible a desprendimientos no solo en la implantación sino también a lo largo del tiempo de la implantación, como consecuencia esto provoca que las ventajas a corto plazo se consiguen una rápida oseointegración del implante, se pierdan a largo plazo con el tiempo en el momento que se dan estos procesos de degradación. 


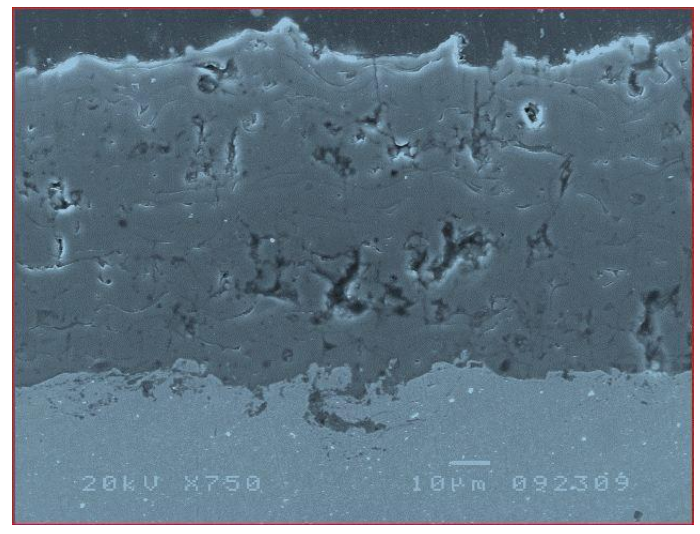

Foto 9.- Corte transversal de superficie recubierta por plasma spray de Hidroxiapatita

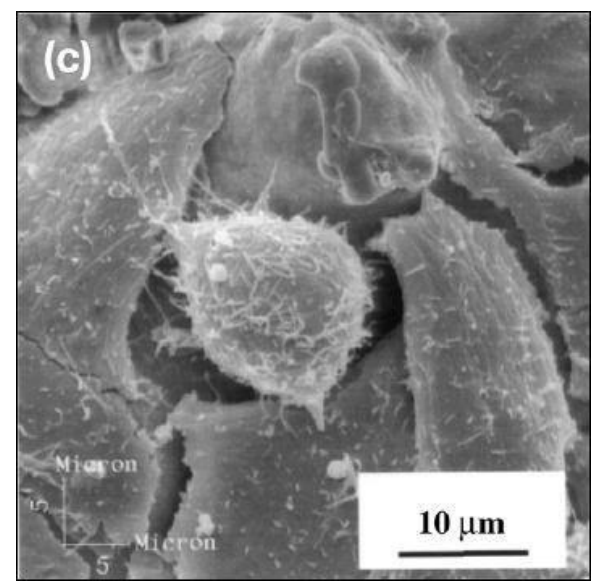

\section{Respuesta del osteoblasto en superficie HA}

\section{Métodos por Enlaces Termoquímicos}

Uno de los objetivos para superar los inconvenientes que presentaba la proyección de plasma térmica de apatita, fue desarrollar métodos, a través de los cuales se podría obtener camadas de apatita o fosfatos de calcio o fluoruros, sobre la superficie del implante por vía química y con enlace químico directo entre el sustrato y el recubrimiento.

Estos métodos se obtienen a temperaturas más bajas para garantizar el enlace químico y poder obtener las ventajas en la oseointegración a corto plazo de un material bioactivo pero sin los inconvenientes que la proyección de hidroxiapatita por plasma pueda presentar a largo plazo. 
Unas de las hipótesis de estos métodos se basan en que la capa de óxido de titanio se forma sobre el metal en lapsos de milisegundos siendo esta capa muy estable, sin embargo, esta capa de $\mathrm{TiO}_{2}$ puede ser mejorada, enriquecida y aumentada, es así que esta camada puede reaccionar con una solución básica de hidróxido de sodio y formar un gel de titanio de sodio, el cual se puede estabilizar, por medio de un tratamiento térmico adecuado, quedando parcialmente cristalizado. Una vez formada esta capa reacciona por medio de intercambios de iones de sodio e $\mathrm{H}_{3} \mathrm{O}$ procedentes de los fluidos corporales. Estas propiedades le dan a la superficie del implante una humectabilidad aumentada que favorece a la adhesión celular.

\section{Métodos por Deposición Electrolítica (Oxidación anódica)}

La biocompatibilidad de los implantes comercialmente puro es bien conocida por las propiedades físicas y químicas de la capa de óxido de su superficie $\left(\mathrm{TiO}_{2}\right)$ principalmente por la relativa característica de inercia química de esta capa de óxido frente a los fluidos biológicos. Debido a esto las reacciones iniciales con los fluidos biológicos, ocurren lentamente en los implantes sin tratamiento de superficie, al modificar la topografía de la superficie y alterando la rugosidad, se consiguen mejoras en la interacción del implante.

Una forma de recubrimiento bioactivo que mejora considerablemente la etapa inicial de la oseointegración son los recubrimientos con hidroxiapatita, pero por un lado estudios demuestran un elevado grado de oseointegración con estas superficies, por otro lado, la adhesión de la hidroxiapatita al sustrato puede fallar y comprometer la estabilidad de la oseointegración largo plazo.

El cambio en la composición química de la camada de óxido tiene la capacidad de influir en el tipo de iones absorbidos durante las primeras interacciones con el medio biológico. La presencia 
de calcio y fósforo en esta capa de óxido aumenta su espesor y pasividad con los medios biológicos, dándole a esta superficie una alta capacidad de atracción y de adhesión de las proteínas presentes en el suero.

Sul (2002) La adición de fluoruros también son empleados para alterar o enriquecer las propiedades químicas y topográficas de los implantes. Estas superficies están demostrando ser eficaces en acelerar y fortalecer la oseointegración en sus etapas iniciales y su resistencia a largo plazo.

La técnica de oxidación anódica consiste en la utilización de un sustrato de titanio comercialmente puro como cátodo (-) y un electrodo de platina como ánodo (+) inmersos en una solución rica en iones de fosfato y de calcio, a una temperatura de 80 grados centígrados y la densidad de la corriente es de 0.15.a 0.3 mA7 cm2 y el PH de la solución es de 3,7. Estas condiciones de la solución favorecen a la deposición de una camada de CaHPO4. Este fosfato de calcio es posteriormente convertido en hidroxiapatita a través de la inmersión en una solución alcalina. $(22,23)$

Una variante es la inmersión en solución de fluoruros, esto consiste en someter la superficie tratada con granallado, acondicionamiento ácido y pasivado con solución de ácido nítrico, para luego recibir un tratamiento en inmersión química, utilizando una solución de fluoruros conteniendo $0.5 \mathrm{M}$ de flúor y $0.5 \mathrm{M}$ de sodio, a una temperatura de $25^{\circ} \mathrm{C}$ durante una hora.

Después los implantes son lavados y secados a una temperatura de $50^{\circ} \mathrm{C}$ por un período de tiempo de 1 hora.

Al comparar una superficie jateada o granallada con acondicionamiento ácido como lo es la superficie SLA esta posee predominantemente $\mathrm{TiO}_{2}$, en contraste con la superficie tratada con 
oxidación anódica (Vulcano o TiUnite) estas poseen micro poros con tamaño de 0,5 a 3.0 um, la capa de óxido posee $\mathrm{TiO}_{2}$ con incorporación de calcio y fósforo por la deposición electrolítica. (Foto 10)
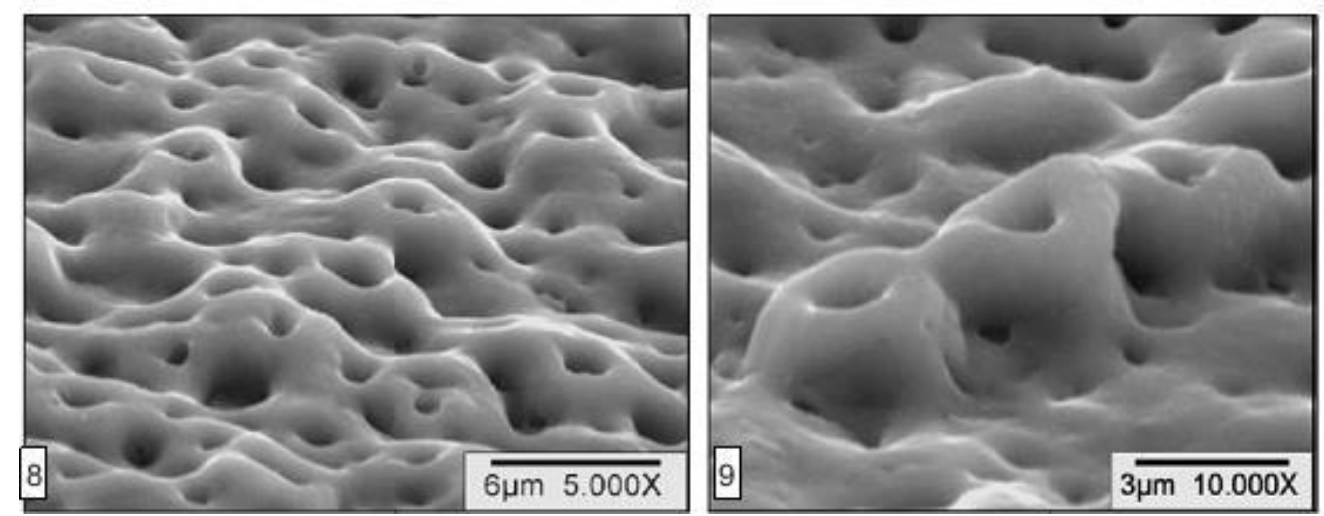

Foto 10.- Superficie tratada por oxidación en solución de Ca + Fósforo. Pinto, L.E.S.C. (2006), “Tratamento Químico da Superfície de Implantes de Titânio”, Dissertação de Mestrado, Instituto Militar de Engenharia/Rio de Janeiro.

Esto hace que la cicatrización sobre estos tipos de superficies sea más rápida en comparación a la superficie maquinada.

Grugel et col en su estudio publicado en el 2008, constatan que, implantes dentales con este tipo de tratamiento de superficie colocados en zonas de defectos óseos creados en canes, presentan mayor porcentaje de contacto hueso implante comparando con implantes de superficie no tratadas.

Sul en el 2006, comparó la resistencia mecánica y la osteoconductividad de los implantes con oxidación anódica versus implantes con doble ataque ácido. Los implantes de superficie anodizada presentaron mayor torque de remoción y porcentaje óseo-implante a las 6 semanas, sugiriendo el empleo de estos implantes para reducir el índice de fallas en cargas precoces.

Los investigadores atribuyen estas propiedades a que la superficie tratada con oxidación anódica posee mayor polaridad que otras superficies lo que causa la absorción de agua y de 
moléculas solubles en agua. La absorción de esas moléculas crea un campo eléctrico con diferencia de potencial a lo largo del espesor de la capa de óxido del implante, la diferencia potencial disminuye, facilitando la humectabilidad consiguiendo así una mejor respuesta biológica.

\section{Conclusiones.}

Los cambios topográficos de la superficie tienen influencia cada vez mayor en la respuesta de las células del hueso receptor con el implante. Estos cambios o mejoras en la superficie Influencian en la absorción de proteínas; mineralización de la matriz extracelular del tejido óseo, la adhesión, proliferación y diferenciación, los osteoblastos.

Características de rugosidad homogénea; energía y composición química mejoran el desempeño de las células en los estadios iniciales de la oseointegración posibilitando la conexión funcional en 4 semanas (superficie anodizada) al igual mejorando la estabilidad inicial y una oseointegración sostenida a largo plazo.

Es necesario continuar con las investigaciones para mejorar la respuesta biológica, evaluar y cuantificar el comportamiento de las nuevas superficies en períodos mayores de tiempo. 


\section{Bibliografía.}

Baldoni M, Ariello F, Favalle P, Bonino GL, Balucchi L, Caccianiga GL, Erindetti A, GraziadeiM. Planificación del tratamiento implantológico. Materiales de implantes (II Parte). Avances en Periodoncia 1999; 11: 9-14.

Abrahamsson I, Zitzmann NU, Berglundh T, Linder E, Wennerberg, Lindhe J. The mucosal attachment to titanium implants with different surface characteristics: an experimental study in dogs. J Clin Periodontol 2002; 29: 448-55.

Albrektsson T, Brånemark PI, Hansson HA, Lindström J. Osseointegrated titanium implants. Acta Orthop Scand 52 (1981) 155-170.

Block MS, Gardiner D, Kent JN, Misiek DJ, Finger IM, Guerra L. Hidroxyapatite-coated cylindrical implants in the posterior mandible: 10 year observations. Int J Oral Maxillofac Implants 1996; 11: 626-33.

Bollen CML, Papaioannou W, Van Eldere J, Schepers C, Quirynen M, Van Steenberghe D. The influence of abutment surface roughness on plaque accumulation and periimplant mucositis. Clin Oral Implants Res 1996; 7: 201-11.

Brunski J, Nancy PD. Biomaterial and biomechanics of oral and maxillofacial implants : current statusand future developments. Int J Oral Maxillofac Implants $2000 ; 15: 15-43$

Brunski JB. Biomechanical factors affecting the bone-dental implant interface. Clinical Mater 10 (1992) 153201.

Buser D, Schenk RK, Steinemann S, Fiorellini JP, Fox CH, Stich H. Influence of surface characteristics on bone integration of titanium implants: a histomorphometric study in miniature pigs. J Biomed Mater Res 1991; 25: 889-902.

Colling EW. "The Physical Metallurgy of Titanium Alloys". American Society for Metals. Metals Park, Ohio, 1984.

Conrado Aparicio Dadenas. Tesis doctoral Universidad Politécnica de Cataluña. Capt \#5 pag: 257 (2004).

Cordoli G, Majzoub Z, Piattelli A, Scarano A. Removal torque and histomorphometric investigation of 4 different titanium surfaces: an experimental study in the rabbit tibia.Int J Oral Maxillofac Implants 2000; 15: 668-74.

Drake DR, Paul J, Keller JC. Primary bacterial colonization of implant surfaces. Int J Oral Maxillofac Implants 1999; 14: 226-32.

Hanawa T. Titanium and its oxide film; a substrate for formation of apatite. En "The bone-biomaterial interface"; ed. Davies JE. University of Toronto Press, Toronto (1991), p. 49-61.

Klokkevold PR, Nishimura RD, Adachi M, Caputo A. Osseointegration enhanced by chemical etching of the titanium surface : a torque removal study in the rabbit. Clin Oral Implants Res 1997; 8: 442-7.

Lee J, Rouhfar L, Beirne R. Survival of hidroxyapatite-coated implants: a meta-analytic review. J Oral Maxillofac Implants 2000; 58 : 1372-9. 
Liao H, Fartash B, Liu J. Stability of hydroxyapatite-coatings on titanium oral implants (IMZ). 2 retrieve cases. Clinical Oral Impl Res 8 (1997) 68-72.

Lima, JHC, Elias, CN, Meirelles, LA. Cap 16: A Osseointegração em Diferentes Tipos de

Superfícies dos Implantes Osseointegráveis. In Odontologia: Arte e Conhecimento. Editores Rielson José Alves Cardoso e Manoel Eduardo de LimaMachado, Editora Artes Médicas Ltda, São Paulo, 2003; p.353- 365.

London RM, Roberts FA, Baker DA, Rothrer MD, O`Neal RB. Histologic comparison of a thermal dual-etched implant surface to machined, TPS, and HA surfaces: bone contact in vivo in rabbits. Int J Oral Maxillofac Implants 2002; 17: 369-76.

Martínez-González JM, Barona Dorado C, Flórez Rodríguez M, Donado Azcárate A, Suárez Quintanilla JM. Implantes con grabado ácido y pasivado químico: estudio preliminarsobre carga precoz. Av Periodon Implantol 2001; 13(3): 9-15.

Novaes AB, Souza SL, de Oliveira PT, Souza AM. Histomorphometric analysis for the bone-implant contact obtained with 4 different implant surface treatmentsplaced side by side in the dog mandible. Int $\mathrm{J}$ Oral Maxillofac Implants 2002; 17: 377-83.

Piattelli M, Scarano A, Paolantonio M, Lezzi G, Petrone G,

Piattelli A. Bone response to machined and resorbable blast material

Pinto, L.E.S.C. (2006), “Tratamento Químico da Superfície de Implantes de Titânio”, Dissertação de Mestrado, Instituto Militar de Engenharia/Rio de Janeiro.

Pinto, L.E.S.C. e Elias, C.N. (2005), "SEM Analysis of DentalImplants Surface After Fluoride Treatment", Brazilian Journal of Morphological Sciences, Sup. 289-290.

Predecki P, Auslaender BA, Stephan JE, Mooney VL, Stanitski C. Attachment of bone to threaded implants by ingrowth and mechanical interlocking. J Biomed Mater Res 6 (1972) 401-412.

Rühling A, Hellweg A, Kocher T, Plagmann HC. Removal of HA and TPS implant coated and fibroblast attachment on exposed surfaces. Clin Oral Implants Res 2001; 12: 301-8.

Sánchez A, Bermejo A. Revisión de los constituyentes implantológicos en función de sus relaciones tisulares. Quitaessence 2001; 14: 68-75.

Sul, Y. T.; Byon, E. S. e Jeong, Y. (2004), "Biomechanical measurements of calcium-incorporated oxidized implants in rabbit bone: Effect of calcium surface chemistry of a novel implant", Clin. Implant Dent. Relat. Res., 6, 101-110.

Sul, Y. T.; Johansson, C. B. e Albrektsson, T.(2000), "Oxidized titanium screws coated with calcium and their performance in rabbit bone”, Int. J. Oral Maxillofac. Implants, 17, 625-634.

Sykaras N, Lacopino AM, Marker VA, Triplett RG, Woody RD. Implant materials, designs, and surface topographies: their effect on osseointegration. A literature review. Int J Oral Maxillofac Implants 2000; 15: 675-690.

Tengvall P, Lundström L. Physico-chemical considerations of titanium as a biomaterial. Clin Mat 9 (1992) 115-134. 
Thomsen P, Larsson C, Ericson LE, Sennerby L, Lausmaa J, Kasemo B. Structure of the interface between rabbit cortical bone and implants of gold, zirconium and titanium. J Mater Sci: Mater Med 8 (1997) 653-665

Wennerberg A, Albreksson T, Andersson B, Kroll JJ. A histomorphometric and removal torquestudy of screwshaped titanium implants with three different surface topographies. Clin Oral Implants Res 1995; 6: 24-30.

Wu-Yuan CD, Eganhouse KJ, Keller JC, Walters KS. Oral bacterial attachment to titanium surfaces: a scanning electron microscopy study. J Oral Implantology 1995; 21(3): 207-13. 